\title{
Reference:
}

Lima, J.; Eusébio, C. \& Amorim Varum, C. (2017). Determinants of leisure expenditure: Do low income families behave any differently from others?, Anatolia, DOI: http://dx.doi.org/10.1080/13032917.2017.1366345

\section{Determinants of leisure expenditure: Do low income families behave any differently from others?}

Tourism is not accessible to all individuals and households. Low income specifically constrains participation in tourism and affects households' level of Leisure and Tourism Expenditure (LTE).

This study uses micro-data available regarding 9,489 Portuguese households, deepening the understanding of the Portuguese reality concerning the households' LTE, its determinants, and how these differ according to the households' income level. Studies analysing leisure and tourism in low-income families are scarce. Low-income families have significantly lower LTE and important differences in the determinants of LTE arise between the groups of families. This deeper knowledge about the households' LTE can form the basis for actions aiming to reduce constraints and encourage leisure and tourism, maximizing the benefits lowincome families can obtain from that participation.

Keywords: Leisure and Tourism expenditure; household income; Portugal; low-income families; determinants. 